\title{
COOC: an Agile Change Management Method
}

\author{
Thibault Le Grand ${ }^{1,2}$ \\ ${ }^{1}$ Centre de Recherche en Informatique \\ Université Paris 1 Panthéon-Sorbonne, Paris, France \\ ${ }^{2}$ Crédit Agricole \\ $C A C I B$, Montrouge, France \\ thibaultlg@gmail.com
}

\author{
Deneckère Rébecca \\ Centre de Recherche en Informatique \\ Université Paris 1 Panthéon-Sorbonne \\ Paris, France \\ rebecca.deneckere@univ-paris1.fr
}

\begin{abstract}
Successful completion of the Industry 4.0 or Future Industry programs requires support for women and men to drive them. The challenge of aligning skills is complemented by the modernization of their practices and tools. All businesses are changing and change management techniques have become standard practice in most organizations. However, the so-called "traditional" methods are limited and it is now proposed change management methods called "agile", borrowing the philosophy of agile development methods to reduce the obstacles to change by injecting a bit of agility in their way of doing things. We first argue about this proposal with the results of a questionnaire to define the importance of people implication in a change project. We then propose a method based on the agile change model [1] by proposing tools adapted to each phase as well as an optimization of the experimentation phase. An evaluation of the proposed method is performed with a retrospective on a real case and the interview of an expert.
\end{abstract}

\section{Keywords-Change management, Agility, Method}

\section{INTRODUCTION}

Change refers to the change from one state to another. Change in a company has its advantages and disadvantages. It can be experienced as a trauma from employees accustomed to a certain routine, methods and ways of working that can be their own. Change can be experienced as a destabilizing, disruptive element, but it also allows a company to adapt to changes in its environment and time. Industry 4.0 raises fears among employees as robots and algorithms were seen, even recently, only as machines dedicated to supplanting humans [2]. This perception has evolved, as individuals see the benefits of digital technology in terms of workplace wellbeing, for example with robotic assistance for handling heavy loads, or with augmented reality for maintenance operations [3]. But even if we have gone from robots called to take up our jobs to concepts of augmented workers, all worries have not been swept away. Individuals remain concerned about the possible disappearance of their position, its obsolescence caused by technology or, at best, its profound transformation.

Before any change, a company must then anticipate future problems related to this change. It must think of the best way to drive the change and have also to implement a specific management to support its employees to combat any change resistance. Change management involves all the operations and actions carried out within an organization to handle the change with its employees and its environment. Organizational agility [4] is the ability of the company to adapt on an ongoing basis in response to an environment characterized by complexity, turbulence and uncertainty. It echoes agile methods, developed for several years in the field of computing and originating from the Agile Manifesto, written in 2001 [5]. It is necessary to see Agile methods more as a paradigm, a state of mind, a philosophy than as simple methods to apply. Change and Agile methods are an inseparable couple. In fact, agile change wants to be an operational and concrete response to all the new problems related to change (more responsiveness, more flexibility for the organization). An agile change management method has already been defined [6] and we propose an extension of this method with (1) the identification of supporting tools and (2) an improvement of the workshops cycle. We also propose an evaluation of our method. The research questions we want to answer in this work are the following. QR1: Does an agile change management induce a better adoption of change? QR2: Does the tools proposed by the COOC method can help to handle an agile change management?

A state of art is given on section 2 about changes and what it entails for the organization, as well as about Agile methods, their inherent concepts and what they bring to a company. A questionnaire to identify if agility could be useful in a change management is proposed in section 3 . The tools proposed by the Concept Of Continuous Change (COOC) method are presented in section 4 and evaluated in section 5 . We conclude in section 6 .

\section{RELATED WORKS}

\section{A. Change, Agility and Agile change management}

In business leaders' speeches, the word Change has become a permanent leitmotif. Executives do not hesitate to present it as a virtually automatic solution to the changing markets, technology, laws or as the necessary dynamics for any business. Often, business managers will say these words "Change or disappear".

However, what is a change? For there to be a change, there must be a significant break in modes of operation. This rupture will force individuals to try to adapt. The transition from the present to the future is not a micro-adaptation that can be regarded as a minor evolution but a real leap that will make obsolete some or even all of our existing way of workings in favor of a new way of doing things, to do better than before. The change will be considered as such if the several elements undergo a transformation, like practices, work conditions, tools, management, business, strategies and so on [6].

Until the late 1990s, the dominant approaches in the development of computer projects were based on the planning and subdivision of the project into sequential lots. Faced with the need for adaptability, continual change and responsiveness imposed by an increasingly competitive technological market, the rather "conventional" methods have been put into question by the emergence of new methods called "agile". These are generally described as iterative, incremental, self-organising and more adaptable to change. Agility can be defined as a response to the widening and hardening of competitive environments that allows to instill in organization, responsiveness and performance [7]. Applied to the software world, the notion of agility refers to the adaptive capacity of 
IT companies and the constantly evolving demands of customers, arriving usually during the project and to a better mastery of the tryptic cost-quality-functional perimeter.

Different models exist to describe changes [8,9]. Resistance to change is defined as any behaviour or attitude that indicates a refusal to support or make a change to a change project [10]. It is necessary to support users in a change project to reduce the possibilities of resistance, and thus to implement a change management approach. There are several "instrumental" change management models [11,12]. These models have several limitations, hence the need for a different and more agile behaviour of change. [1] explains these limitations: (a) the linear structuring that creates tunneling effects between beneficiary engagement and when the change will be real for them, (b) "the dictatorship of the Powerpoint" as many productions describe the existing in an analytical way without always giving action keys that will put the beneficiaries in a dynamic of transformation, (c) the low participation of beneficiaries.

A particularity of agile methods that characterize agile change management frameworks and methods is to put human on the center of the change. The concept of people-centered change, using user-centered design, believes in one fundamental truth: gather success when starting with the user, finding a real user need and then building a good solution [13]. Following this philosophy, agile change management frameworks and methods began to appear in the last decade. For instance, the Accelerating Implementation Methodology (AIM) is a flexible change management framework for managing organizational changes, designed to be able to handle change as it continues to evolve [14]. One of its main advantages is that it focuses on the human-side of the change, as do all agile methods. Highly scalable, this framework may be considered quite complex and sometimes difficult to handle. [15] proposed an agile change management approach which is less complex and easier to use. Experimentation and change management are at the heart of this model, with scoping elements and an anchor in connection with transformation strategies and development, with the people affected by the change, their ability to change.

\section{B. The Agile change management model}

In the Agile change management model [1][15] the link between the business line and the change is essential, it is not just necessary to "change to change" because the change will always bring added value to the business. We want to change in order to do better in the value-creating activity, thus the business or trades of the company. The use of workshops of various forms makes it possible to give back an active part to the trades in the management of change. The people in charge of change management will have to propose devices for diagnosis, steering and change workshops for the people who are in the trades and through which the change is realized.

The model consists of three phases: Define, Experiment, Anchor. The first two phases ("Define" and "Experiment") concern a project or clusters of projects included in a program while the "Anchor" phase is at the level of the organization as a whole. In this last phase, we look at how the different plans for change fit into a dynamic of collective transformation, both at the level of the company's overall project as well as the ability to change individuals and the company.

The "Define" phase is carried out upstream of the project, before its launch or at the beginning of the project. During this phase, we seek to establish a roadmap that we will follow throughout the change project. This is a diagnostic phase, we try to turn the discourse of change into a roadmap. The latter is extremely important for the smooth running of the project. It's a phase where we have to ask questions, the right questions to be answered in order to define the changes, the context and the actors involved. This phase of Agile change does not differ greatly from the classic conduct of change.

The "Experiment" phase is at the heart of the agile change model. It consists of two cycles that combine and complement one another: a series of workshops (participatory workshops and participatory cycles) and a control cycle. The cycle of workshops allows stakeholders to become aware of the need for change, to involve stakeholders in the design of change, involving all stakeholders and bringing change to the actors rather than putting them through it. The control cycle consists in carrying out, at different intervals, measures of change in progress, and the means of surveying individuals who are beneficiaries of change. These surveys can be conducted through discussions on a company's social network or through interviews via questionnaires. Through piloting, information is available on the progress and adoption of change, and this will allow us to assess and measure the contribution of actions to support change. It is advisable to do these surveys, used to produce indicators, every two to four months depending on the significance of the change project.

The anchor phase is essential if change is to be sustainable in the company. Change projects are often criticized because they mobilize resources for projects that remain in the state of discourse, or that are overnight changes. Individuals affected by change devote energy to change, and this expenditure must not be in vain, both for the individual and for his enterprise, but must be used to capitalize on the changes made in order to build the future of the company. Two productions come from the anchor phase: a global vision, at five years, of the projects carried out, in progress and to come, as well as an analysis of the ability to change the company.

\section{A BIGGER IMPLICATION OF PEOPLE?}

An agile change management implies a bigger implication of involved people. In order to know if a bigger implication in a change will help to handle the change project, we diffused a questionnaire which have been answered by 104 persons. Table 1 presents the questions of the questionnaire. Some questions are conditioned by previous answers.

TABLE I. QUESTIONNAIRE

\begin{tabular}{|l|l|}
\hline & \multicolumn{1}{|c|}{ Question } \\
\hline 1 & Gender? \\
\hline 2 & Age? \\
\hline 3 & Socio-professional group? \\
\hline 4 & $\begin{array}{l}\text { If there is ever a change in your professional life, would you be } \\
\text { more inclined to adopt a change that you yourself have designed? }\end{array}$ \\
\hline 5 & $\begin{array}{l}\text { Do you think that consulting the people affected by the change on } \\
\text { several occasions will result in an extra cost (time, financial ...) } \\
\text { for the company? }\end{array}$ \\
\hline 6 & $\begin{array}{l}\text { Did you ever experience a situation of change in your working life } \\
\text { (transfer, merger, adoption of new working methods, geographic } \\
\text { mobility)? }\end{array}$ \\
\hline 7 & Did you welcome positively this change? \\
\hline 8 & $\begin{array}{l}\text { Did you have the opportunity to give your opinion, to be } \\
\text { consulted during this period of change? }\end{array}$ \\
\hline 9 & $\begin{array}{l}\text { Would you have liked to be consulted about the change you } \\
\text { experienced? }\end{array}$ \\
\hline 10 & Do you think your opinion has been taken into account? \\
\hline 11 & Do you think this helped you to accept and adopt change? \\
\hline
\end{tabular}


The panel of respondents to the questionnaire consisted of 104 persons from 7 socio-professional categories, although a majority of professionals and senior managers responded to the questionnaire. The gender distribution is around 60/40. The majority of the panel consisted of persons between the ages of 21 and 60.

About $95 \%$ of respondents had already experienced a change in their working life, which supports the theory that the business world is constantly evolving and changing. Working for 40 years in the same company, at the same post became utopian in today's world.

\section{A. Questionnaire results}

Approximately $97 \%$ of respondents would be more inclined to adopt a change they have designed. Participating in the change project and helping to develop and design it, through the various participatory workshops and the "Experiment" phase of agile change, is one of the foundations of an agile change.

Approximately $85 \%$ of respondents believe that consulting the people affected by the change on several occasions during the change project will result in an extra cost to the project. This is significant and the lesson can be drawn from this is that leading a change project by implying people could result in an overcharge for the project. However, these comments can be nuanced because the time and money spent during the project, for change management, can be considered an investment because it will greatly reduce the resistance to change of individuals, and therefore change will be more easily adopted. It is time and money that we are spending earlier in order to have a brighter future.

We can look more closely to the 19 people having already experienced a change situation in their professional life, and having positively welcome this change. Of these people, twothirds had the opportunity to give their opinion, to participate in the change. Another information given is that two-thirds of these people consider that being able to give their opinion on the change, participating in its development, helped them to adopt and accept the change. We can say that people who had the opportunity to give their opinion, to participate in the change had more facilities to adopt the change.

However, all of these 19 persons are medium or high levels executives, this may be considered as one of the criteria for a good change adoption. If we study more closely the set of people which are "basic" employees, we can see that all people who had experienced a situation of change in their professional lives ( 7 persons), did not positively accept the change. Moreover, none of them had an opportunity to comment on the change.

Of the 104 respondents in this questionnaire, 84 people experienced a change in their working life and did not have the opportunity to give their opinion or be consulted about the change that would be made in their companies. Of these 84 persons, 96\% would have liked to be consulted. Another observation can therefore be made, the various times when individuals affected by change will have the opportunity to express their feelings, reservations and ideas about change, are important. These individuals are consulted in order to improve the current change, so that all stakeholders in the change project are satisfied.

$100 \%$ of the people who had the opportunity to give their opinion on the change and to participate in its design (14 persons) find that it helped them to accept and adopt the change. Involvement of individuals involved in change in the development of the change project therefore helps them to adopt and accept change. Moreover $80 \%$ of them welcomed the change positively because they had the opportunity to give their opinions on the change. In the same line, $100 \%$ of the individuals interviewed said they were more inclined to adopt a change they themselves would have designed.

It is noticeable that people in the age bracket between 61 and 80 would be more inclined to adopt a change designed by themselves, to the tune of $75 \%$. When one looks at the age group between 21 and 40 years old, this figure rises to $99 \%$. Age can then be a criterion to consider. Faced with age, agile change is a response that may see its influence decrease as the age of the individuals affected by the change increases.

\section{B. Conclusion on the questionnaire}

The questionnaire showed that the panelists were rather convinced of the benefits of people implication in a change project. Each question asked referred to one of the key concepts of agile change, such as the involvement of the individuals involved in the change in the development of the change. Responses to the questionnaire also highlighted criteria that may positively or negatively affect the adoption of business change: Socio professional category and age of individuals affected by the change and cost allocated to the change project.

We can conclude from this study that an agile change management should allow a better adoption of the change. This conclusion has to be nuanced according to the various criteria determined previously which will positively or negatively influence the adoption of the change.

\section{THE COOC METHOD}

The questionnaire showed that a bigger implication of the employee in the change project helps to have a better change management. It means that an agile change management - as agile implies exactly this concept of employees implication should help a change project. The methodology proposed by $[1,15]$ provides the basis for a change management approach incorporating the principles of agility. Some techniques are recommended by the method but here we propose a set of tools that can be used to implement these techniques, each phase of the method having its own tools that will allow to produce deliverables that will in turn meet the objectives of each phase. Fig. 1 shows the summary diagram with the tools, recommended by the COOC method, to be used in each phase.

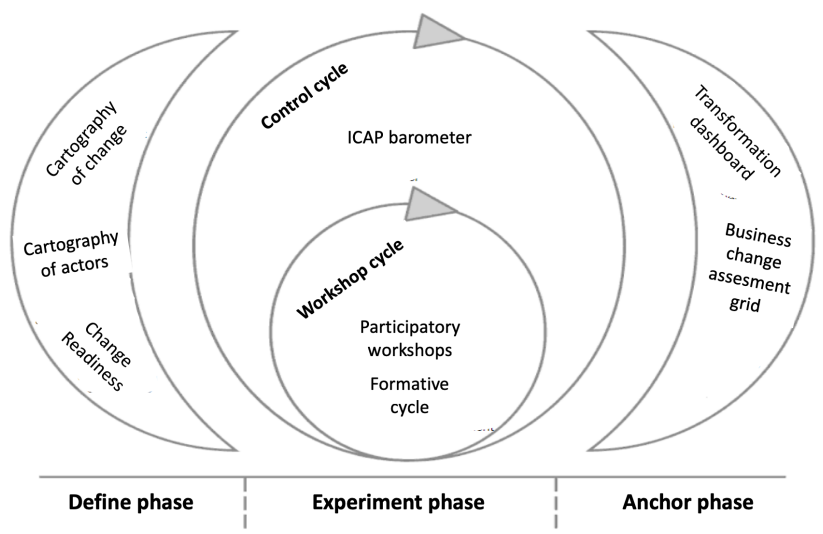

Fig. 1. Tools of the COOC method - based on [1] 


\section{Define phase}

Change management consists in a set of methods, processes and tools that will diagnose a situation of change and propose a number of actions to support and control change. The main objective of most methods is to limit the resistance to change of beneficiaries affected by change. There are several ways to limit aversion to change, the conduct of instrumentalized change makes use of communications, training and accompaniment plans. This can also be done through managers, who can be trained to be true relays of change. Each manager will then be seen as a change facilitator, they will facilitate change with their employees.

In all cases, the conduct of change is embodied in tools and methods that require time and key skills. We have to consider that these tools are sometimes long and costly to put in place in a company. It can lead to some form of inoperative, timeconsuming bureaucracy, never really implementing change.

\section{1) Cartography of Change}

Cartography of change has been used for different objectives $[1,16]$ but it is always a technique to describe the change. It is a tool that qualify the changes to assess the envisaged change extent and to determine which risk areas should be treated or avoided. This tool is organized around five main themes: organization, functioning, tools, competencies, culture and behavior. We propose to address these themes by asking the questions listed in Table 2 .

\section{TABLE II. QUESTIONS TO DEFINE THE CARTOGRAPHY OF CHANGE}

\begin{tabular}{|cl}
\hline Organization & $\begin{array}{l}\text { Will the structures in place be changed by the change, } \\
\text { will there be creation, deletion or modification in } \\
\text { terms of the power and scope of activities of certain } \\
\text { branches, services or units? }\end{array}$ \\
\hline Functioning & $\begin{array}{l}\text { Will existing practices and ways of doing have to } \\
\text { evolve in such a way that people will have to } \\
\text { completely change their ways of doing things? }\end{array}$ \\
\hline Tools & $\begin{array}{l}\text { Will there be new tools driven by change? What } \\
\text { impact the use of these tools will have on the daily } \\
\text { functioning, the organization of work and the } \\
\text { competences of the different actors? }\end{array}$ \\
\hline Competencies & $\begin{array}{l}\text { Will people affected by change have to acquire new } \\
\text { skills both technically and managerially? Do the } \\
\text { change will lead to suppression but also to the creation } \\
\text { of new trades? }\end{array}$ \\
\hline Culture and & $\begin{array}{l}\text { Is the project of change predicting or necessitating } \\
\text { major behavioral changes? Will the culture of the } \\
\text { company evolve and to what extent? }\end{array}$ \\
\hline
\end{tabular}

Cartography of change helps to identify "areas of change", such as areas of significant change and the area of change affecting all actors of change. This analysis in terms of targets (actors) and significance will thus make it possible to propose an accompaniment adapted to each type of actor of the change. This cartography is carried out at the beginning of the project, but its content must be reviewed and updated regularly. Actions, such as accompaniment adapted to each type of actor, should therefore also be updated. It is through these continuous enhancements that we can talk about agile change management. The cartography is usually carried out in a small, small committee, consisting of the change management team, project team members and business leaders. The mapping of change is not a secret document, but must remain discreet.

\section{2) Cartography of Actors}

[9] proposes to carry out a cartography of actors that makes it possible to identify and them. We propose to characterize each actor with the following characteristics: type, number, location, role, importance degree and risk level.

The concerned persons are grouped by typology according to the homogeneity of their behavior with regard to the change or according to the title of their trade. It is strongly advisable to adopt the typology by trade, because people in the same trade will often find themselves with the same problems, the same questions and therefore the same behaviors in the face of change.

The concept of number makes it possible to understand how many individuals are affected by the change and thus the volume of accompanying actions that will have to be carried out: $<50$ individuals (actions in participatory mode), $>50$ individuals (direct participatory-type actions are much more difficult to implement. These groups must then be divided into smaller groups so that this type of action can be envisaged), > 100 and not breakable down into smaller groups (the measures envisaged must have an industrial dimension and can be addressed to the recipients in a uniform way).

The location of the actors is simply the place where the actors carry out their activity. Classifying the actors through the location of their place of work will make it possible to better organise the actions envisaged, especially in the case of a large company with several buildings scattered throughout a region or country.

There are different levels of roles, from most to least important: sponsor (whoever wears and wanted the project), level 1 relay (individuals facilitators of change - managers), level 2 relay (individuals helping level 1 relays in change assistants), beneficiaries (individuals benefiting from change).

The degree of importance of an actor in the change project characterizes the level of influence of individuals in the success of the project. There are three levels of importance: Essential, Important, Unimportant.

The level of risk qualifies the categories of actors vis-àvis their acceptance of the change project. There are three levels of potential risk: Acceptance, Modification, Refusal. If actors whose degree of importance is essential or important have a level of risk equal to the refusal or modification, this represents an area of risk which will have to be considered in the actions envisaged for the conduct of the change. For the actors requesting the modification, it is then necessary to assess the level of modification expected by the latter. If the requests are of the order of a complete reconfiguration of the change project itself, it will be difficult to accept them. On the other hand, if the requests relate to existing practices that the actors wish to retain, it is quite easy to resolve them by taking them into account in the change project or by working with the people concerned, to show them the interests they would have to change. It is a kind of negotiation during which a compromise must be found so that the level of risk of the actors is a level of acceptance.

The document produced by the cartography of actors is carried out at the beginning of the change project and must be regularly updated by the team in charge of the change management project, throughout the course of the project. Like the document produced by the cartography of change, it is a document that is not secret but must remain discreet. The main objective of this document is to establish the magnitude of the change and the categories of actors according to their importance and their position with regard to the change project 
but also the various influencing will be able to lend themselves the relays and sponsors of the project.

\section{3) Change Readiness}

The Change Readiness $[17,18]$ is a tool for carrying out an analysis of the factors of acceptance or, on the contrary, of refusal of the change. This tool comes in the form of a questionnaire that will detect project specific elements that will be levers or brakes for change. Each answer is generating points and it results in twenty transformative scores. A project is then considered strategic in terms of change if the score is greater than ten. Table 3 proposes a set of questions summarizing several questionnaires found in the literature.

TABLE III.

CHANGE READINESS QUESTIONNAIRE (BASED ON $[15,16]$ )

1 Will the change project result in job losses?

2 Will the change project result in geographical and functional mobility constraints for a large proportion of the beneficiaries?

3 Will the change project last more than 36 months?

$4 \quad$ Will the change project lead to major changes in the culture and behavior of employees in the company?

5 Does the change project involve the entire company?

6 Is the change project carried by the company management?

7 Will the change project change existing management power zones?

8 Is the project clearly linked to the company's strategy?

9 Does the project have formal stages of implementation?

10 Is there internal competition (between services or between people) for the realization of the change?

11 Does the management of the company give enough importance to the change?

12 Does the company have a practice and experience in leading change?

13 Does the company have mobilizable methods and resources for change management?

14 Will managers be co-builders and good relay to change?

15 Are the jobs affected by the change driving the change project?

16 Do individuals affected by change have a culture of change?

17 Does the company have a clear and legible transformation policy?

18 Does the company find itself in a situation of saturation concerning change?

19 Has the company recently experienced a traumatic change?

20 Is the company able to recognize individuals who are involved in change projects?

\section{Experiment phase}

The experiment phase is organized around two cycles, the control cycle and the workshop cycle, in parallel and interdependently.

\section{1) Participatory Workshops and Formative Cycle}

Participatory workshops [19] are at the heart of the dual cycle of experimentation/piloting. These are times when the beneficiaries of change, whether they are managers or not, and the people in charge of change work hand in hand in the perception, understanding and realization of change. Each workshop is a working session differentiated according to its objective. There are five types of participatory workshops, each with different objectives and different timing: catharsis (to formalize feelings, fears, frustrations or possible discontent), brainstorming (to express creativity, to make proposals that should not be criticized, so other participants can bounce on them and propose in turn other ideas that may be related to the previously proposed idea), exploration (to define possible solutions), proposition (to take decisions and commitments about the solutions) and experimentation (to experience the change through a kind of simulation of change or role play).

The participatory workshops [9] allow the different participants to tame the change, but also to learn the new ways of doing things related to the change. However, sometimes these schemes may prove insufficient for the beneficiaries of the change who may wish to take training to learn or integrate these new habits or gestures. Formative cycles [9] thus complete the cycle of participatory workshops. When training is programmed in the conduct of change, the target must be defined.

Three types of training program can be distinguished: Collective, by relay and individual training. Collective training involves training all individuals within a specific functional perimeter. All those involved in training must follow it with degrees of deepening which may differ according to their role and activity. This type of training is widely used for computer related training or awareness, but it is much less interesting and relevant for organizational or cultural projects. Relay training consists of training only a few people with a high level of expertise so that they can then redeploy and dismantle the training to other people. This type of training requires two stages of achievement, one to train the relays, and a second for the relays to train other employees. These people will then play the role of referent after the end of the change project, they will have the original knowledge of change. Individual training may be similar to tutoring or coaching. This device is adapted when there are relatively few individuals to take the training. The instructor will have to be particularly pedagogical and will have to have practical cases solved by the people he is responsible for, while presenting concepts and methods to resolve the same cases.

The original agile change model [6][1] does not provide guidance on the sequence of the participatory workshops and does not specify when the formative cycles are to be introduced, or when the model is to be introduced. In addition, the agility of the model lies only in the repetition of the cycles of workshops and steering. The COOC method recommends that the different types of participatory workshops should be carried out on a specific cycle that can be repeated until a sufficient level of satisfaction is obtained for all stakeholders. The cycle of the participatory workshops begins with the catharsis workshop, and then leads to a cycle consisting of three bricks: the brainstorming and exploration workshops make up the first brick, the proposed workshops are located in the second and the experimentation workshops in the third. Thus, little by little and incrementally and iteratively, we manage to please and involve all the different stakeholders of the change project.

The first brick of this iterative cycle is therefore composed of the Exploration and Brainstorming workshops. This minicycle have to begin with a Brainstorming workshop so that participants can share ideas together and then deepen them during the Exploration workshops. In the latter, new ideas can emerge and the mini-cycle Brainstorming/Exploration starts again. Once the stakeholders at the workshops have been satisfied, the other two bricks, Proposal and Experimentation workshops, can continue. At the end of these Experimentation workshops, stakeholders can see that the change tested during these workshops is wrong or lacking something. The COOC method allows them to go back on an Exploration/ Brainstorming-Proposition-Experimentation cycle. It is then possible to iterate over several cycles of workshops and to 
improve or increment the change project with new ideas in order to make it ever more satisfying for the different stakeholders and individuals concerned by the change. The end of the workshop cycle is reached when a level of satisfaction is achieved by all stakeholders.

Fig. 2 shows the sequence of the different types of workshops. It is an ongoing cycle for continuous improvement in the conduct of change. People affected by the change have a say in the change, considering their opinions and ideas, this makes it possible to put in place "tailor-made" change management systems for the company concerned.

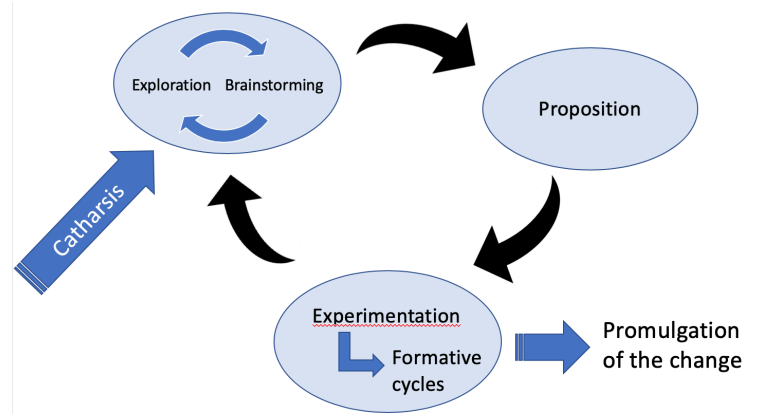

Fig. 2. Recommended cycle for Participatory workshops and formative cycles

Although it is a so-called "learning" step, it may happen that the individuals concerned by the change, after having experienced it, express the need for training moments in order to become even more familiar with the change, in order to integrate it. These courses must be included in the training cycle. The formative cycle must take place between Experimentation workshops and change promulgation.

The workshop cycle is supplemented by the control cycle which runs in parallel.

\section{2) ICAP Barometer and Control Cycle}

The ICAP barometer is a tool developed by [6,9], which takes place during the steering cycle, itself taking place in parallel with the workshop cycles. Steering actions must be carried out throughout the duration of the project in order to have a dynamic, representative and relatively often updated view of the acceptance of the project. The ICAP barometer is used to evaluate the change with four rates (Table 4) calculated at different phases of the project. The values obtained must be compared with desired theoretical values, which will make it possible to assess the level of each of the indicators, the level of achievement of the change but also the effectiveness of the communication levers, training and support. The ICAP barometer must be formalized several times during the project through the conduct of surveys, conducted quarterly and/or at the end of each phase of change, among the individuals affected by the change.

Leading the change through the ICAP barometer means calculating indicators at a certain time. Each indicator will be produced using four questions with four possible answers. The ICAP barometer calculates four rates: the rate of information, understanding, adhesion and participation. Information rate informs about the quality of communication. The values are based on a linear evolution of the information. The information curve must be gradual and constantly evolving until the deployment phase. The more we move forward in the project, the more communications actions must take place and the more the project must be known. Understanding rate evolves in increments according to the clicks of perception of utility and interest that emerge from situations of training, learning. As with the rate of information, the evolution of the rate of understanding must also be linear but less rapid, more gradual than for information. Adhesion rate returns to the learning curve of change: after an euphoria linked to the beginning of change, a decrease follows because of the constraints encountered in practice. This decrease is observed during the period of exploration (or brainstorming). This rate re-increases during the experiment phase. Participation rate tends to follow a yo-yo curve because the individuals involved in the change cannot devote themselves entirely to the realization of the change, they alternate the times dedicated to change with their daily activity, increasing the time allotted to change as they go along. Questionnaires for the desired rates and rate values are summarized in Appendix A.

\section{E. Anchor phase}

The "Anchor" phase is the last phase of the agile change model. The latter is not to be carried out during a specific project but more on all the projects carried out for the transformation. Its objective is to define the vision of the company's completed, ongoing and future projects and to analyze and determine the ability to change the company.

\section{1) Transformation Dashboard}

The transformation dashboard [6], without going into every detail of the projects, give an inter-project vision on what is needed to drive transformation in the company. Its objective is to represent the change trajectory in progress and consists of building a database of the company's projects.

It contains the change project name, its start and end dates, the trades concerned by the change, the number of people impacted, the project state (ended, current, to come) and the different themes concerned by the change: (a) Culture and values: the cultural codes of the company but also the routines and symbols that form the identity of the company and what it is and represents, (b) Customers, markets and products : deal with the external dimension of the company, its business environment, (c) Organization and computerization : Is the change organizational and/or IT? (d) Management and skills: deal with the "Human" and managerial aspects of transformation: managerial skills, roles of managers, skills management for all employees in an organization.

In addition to the dashboard, the second tool that can be used is the Business Change Assessment Grid.

\section{1) Business Change Assessment Grid}

The ability of an enterprise to change is the ability of the enterprise and its members to create the conditions for change, to promote its deployment and integration into the very functioning of the organization. As stated above, the change can no longer be considered a temporary state between two periods of stability within the company. The latter must enshrine change in its DNA because it will enable it to survive, to continue to exist and to remain competitive in an increasingly globalized market.

The assessment grid for the ability to change an enterprise $[20,21]$ is organized around three main areas: context, content and process. The Context echoes all the internal and external elements that will have an influence on the importance that the salaried individuals will attach to the notion of change. This will require consideration of whether there are elements 
within or outside the organization that will positively or negatively affect its ability to change. The Content corresponds to the reservoir of change management skills that the employees of the organization are building up to the progress of the various changes they are experiencing. The Process refers to the mobilization of corporate resources to resolve change situations within the organization. The notion of process corresponds to the actions to do for change.

The purpose of the evaluation matrix (see Appendix B) is to provide a score of 45 to assess an organization's ability to change. Each axis of the evaluation grid is scored on 15 points. There are 5 questions per axis and there are 4 possible answers for each question. Below 15, the ability to change your organization is low; between 16 and 30 , the ability is medium; above 31 , the ability is good.

The assessment of an organization's ability to change should be carried out, at best, every three years in order to be able to consider actions that will improve the ability to change the company. The main objective is to commission actions (workshops, training, scenarios, role-playing) so that change is no longer occasional but usual for employees.

\section{EVALUATION}

In January 2018, the employees of the Information System Management department of a French bank (let's call it BANK A) were all transferred to another entity of the bank group (let's call it BANK B), in the IT department of this entity. This change has been experienced and is now effective and promulgated within these companies.

Our evaluation was performed in two steps. (1) First, a retrospective on this change, in order to determine the actions or elements that could have been better performed as well as the employees' feelings at the time of the change. This retrospective leads to an imaginary project which could have happen if the agile change management had been used. (2) Secondly, an interview of an IT project manager of the bank, who has experienced this change in order to present him the agile change model and the COOC method to obtain an external opinion that may allow to raise areas for improvement or points of attention about the COOC method.

We will begin with a retrospective on the change made within the bank. Then we will see how the agile change and the COOC method could have alleviated or avoided the various problems encountered during this change project.

\section{A. Real facts}

Between July 2017 and January 2018, employees in BANK A IS department were waiting for a change that would profoundly transform their daily lives. Approximately 200 employees were transferred to another entity of the group: BANK B. This change project was managed using a rather conventional change management (Scoping, Information, Deployment). Table IV shows the periods lived by the employees as well as the various findings.

The project scoping period ended before the announcement of the change to employees and no specific start date for this period is available. Numerous corridor noises circulated during this period, it was a real period of instability that had the consequences of creating uncertainties for the employees. The change was decided at the top of the company and no information was disclosed to the other collaborators who were going to be affected by this change.

\begin{tabular}{|l|l|l|}
\hline \multicolumn{1}{|c|}{ Phase } & \multicolumn{1}{|c|}{ Period } & \multicolumn{1}{c|}{ Objectives } \\
\hline Scoping & $<$ july 17 & Define the outlines of the project \\
\hline $\begin{array}{l}\text { Information } \\
\text { part 1 }\end{array}$ & $\begin{array}{l}\text { July to } \\
\text { sept } 17\end{array}$ & $\begin{array}{l}\text { Announcement of change to employees } \\
\text { without setting terms and conditions }\end{array}$ \\
\hline $\begin{array}{l}\text { Information } \\
\text { part 2 }\end{array}$ & $\begin{array}{l}\text { Sept to } \\
\text { dec } 17\end{array}$ & $\begin{array}{l}\text { Announcement of the modalities of the } \\
\text { change }\end{array}$ \\
\hline $\begin{array}{l}\text { Deployment/ } \\
\text { promulgation }\end{array}$ & $>$ jan 2018 & Promulgate the change \\
\hline
\end{tabular}

This was followed by the information period, which was deliberately divided into two distinct phases. The first part of the information phase took place from July to September. The employees were informed, through a conference in an auditorium, that there was going to be a change and that they were going to be transferred to another Crédit Agricole group entity, in this case CACIB. However, it was an announcement with no details as to how this change would take place. This only accentuated the blurred areas around this change project, among the employees. The latter did not have access to any information about the change, which only increased their sense of instability, and the company's daily activity slowed during this period. Throughout the change project, employees developed a certain reluctance to change, which would later lead to an aversion to this change.

From September to December 2017, there was the second part of information period, where employees were informed of the terms of the change, how and when the change was to be made. The employees had many questions, which remained unanswered by the change teams. This only increased the reluctance of employees to change. Most even felt a sense of abandonment from the HR department of their future former company (Crédit Agricole SA). At no time did the employees have the opportunity to get involved in the change project.

Finally, the project deployment period ran from January 1, 2018 , to the present, with the objective of promulgating change, implementing it. Individuals affected by this change were unaware of the new business and new tools (Project Imputation Tools, Project Management Methods, etc.) had to be taken over. Some employees had the opportunity to train in these new tools but not all of them. This was a new period of uncertainty for all employees. The former employees of BANK A and new employees of BANK B did not, for the most part, have the opportunity to meet their new colleagues of BANK B. All these findings have led to a real resistance to change on the part of the individuals concerned by the change, and many of them have gone to another of the group entities or even to other companies.

\section{B. Hypothetic application of the COOC method}

Let's look to this change and how it could have been handled with the COOC method.

\section{1) Define phase (equivalent to the phase Scoping)}

This period, had the project been carried out using the COOC method, would have allowed the change teams to communicate a certain amount of information to the concerned collaborators. Waiting time would certainly have been less important for employees before getting information about the change. The agile change will not be effective for rumors and lane noises, however these will be mitigated as the change and its terms will be announced simultaneously. Table 5 shows what happens versus what an agile change could have improve. 
TABLE V.

DEFINE PHASE COMPARISON

\begin{tabular}{|l|l|}
\hline \multicolumn{1}{|c|}{ Facts } & \multicolumn{1}{|c|}{ Agile change contributions } \\
\hline - Many rumors & - Change announced at the end of the \\
- Uncertainties for employees & "Define" phase \\
- Lack of information & - Procedures for implementing the \\
- Sensations of clutter. & change announced at the end of the \\
& "Define" phase \\
\hline
\end{tabular}

2) Experiment phase (equivalent to the phase Informationpart 1 and 2)

The two parts of the Information Phase have been voluntarily grouped together as they are part of the so-called experimental phase or "Experiment" of agile change. They correspond to both parts of the project information period. Through the Experiment phase, during the workshop cycle, employees will be able to get the answers to their questions and the information they want and thus reduce their worries.

The various participatory workshops will enable them to reduce their fears and involve them in the heart of the change project, transforming them into actors of change. At the same time, the steering cycle will enable the change teams to carry out more or less change actions (participatory workshops, trainings, sensitizations, etc.) in order to obtain a level of information, understanding, adherence and satisfactory participation. The employees' opinions will therefore be taken into account for the change, this will enable a change management and a "over-tailor-made" change for the company and its employees. Future teams (composed of former BANK A employees and BANK B employees) will also be able to get to know each other and discuss their activities and problems encountered during these workshops. This will have the effect of strengthening the links between the employees but also of cross-linking the knowledge between the teams. By making them test and experiment with change, workshops, more playful than simple training, would have made it possible to reduce the various aversions to change developed by employees, as shown in Table 6 .

TABLE VI.

EXPERIMENT PHASE COMPARISON 1

\begin{tabular}{|l|l|}
\hline \multicolumn{1}{|c|}{ Facts } & \multicolumn{1}{|c|}{ Agile change contributions } \\
\hline - Concerns of employees, & - Information obtained during \\
Blurred Situation & participatory workshops \\
- Lack of information, & Concerns reduced through \\
Business activity slowed & participatory workshops \\
- Employees reluctant to get & - Opinions of employees taken into \\
involved & account \\
- Choice not given to & - Employees become actors in their \\
employees & change \\
- Numerous questions raised & - Ownership of change by employees \\
by unanswered employees & - The steering cycle will enable a \\
- Feeling of abandonment & customized change management \\
- Lack of information & - Fears and blur reduced thanks to \\
- Employees are undergoing & participatory workshops \\
change & - The newly created teams will be able \\
- Numerous aversions to & to meet as soon as these workshops are \\
change. & held. \\
\hline
\end{tabular}

\section{3) Experiment phase (equivalent to the phase Deployment)}

Table 7 shows the possible improvement of the use of an agile change in this phase. Deployment or promulgation of the change would have occurred during the experiment period. The various participatory workshops, aimed at experimenting with change, would have made it possible to inculcate change among the individuals involved. The change would have been more progressive and less brutal. In the agile change, the deployment of the change takes place during the experimentation phase, the deployment phase, experienced in the case of Crédit Agricole, would not have existed had this change project been conducted using the agile change model and the COOC method. There would certainly have been fewer departures or requests for departures from individuals affected by the change, but also fewer resistances to change.

TABLE VII.

EXPERIMENT PHASE COMPARISON 2

\begin{tabular}{|l|l|}
\hline \multicolumn{1}{|c|}{ Facts } & \multicolumn{1}{|c|}{ Agile change contributions } \\
\hline - Lack of information & - The deployment would have \\
- Many new tools to adopt & been experimented during the \\
- Blurred Situation & $\begin{array}{l}\text { experimentation phase } \\
\text { (participatory workshops), so the }\end{array}$ \\
- Lack of knowledge of new business & change would have been gradual \\
- Lack of knowledge of new & and less brutal \\
colleagues & - Familiarization of new tools on \\
- Lack of team alignment & the part of employees during the \\
- Many Resistance to Change & experimentation phase. \\
- Numerous requests for departures.
\end{tabular}

\section{4) Anchor phase}

It was useful to add the "anchor" phase in the grid of potential inputs of agile change. This phase did not take place and therefore did not really exist in the facts described. This phase would have allowed absolutely all employees of the company to anchor the change in their DNA and that of the company. This would have made it possible, in the near future, to live change better and thus reduce the various resistance to change encountered (table 9).

TABLE VIII.

ANCHOR PHASE COMPARISON

\begin{tabular}{|l|l|}
\hline \multicolumn{1}{|c|}{ Facts } & \multicolumn{1}{|c|}{ Agile change contributions } \\
\hline - Employees and managers & - Habit of change \\
unaccustomed to change & - Anchored change in company DNA \\
& - Change becomes customary for \\
& employees \\
& - Less resistance to change. \\
\hline
\end{tabular}

\section{5) Conclusions on the case study}

Analysis of this case study highlighted the inputs related to the use of the COOC method and agile change as part of a change project or inducing a change in the enterprise. The key point corresponds to the various workshops of the experiment phase, which make it possible to involve individuals in the change, thereby reducing frustrations, Questions and different aversions to change. During a career, there is a good chance that an employee will be confronted with a major change, so involving him in the change, ask for his opinion and listen to him will allow him to better live the change. His company will also be satisfied because an employee feeling happy and considered in his work will exploit all his potential at the service of his company.

\section{Interview of an IT manager}

The interviewee was responsible for production management and technical support in the BANK A. During his career, he had the opportunity to live and lead several projects involving a change management but also to live several change projects.

For our interviewee, there are four main objectives when carrying out a change management, the first is to explain the change to the people who will be impacted by it, then explain to them the issues of the change, why we want to change, and 
then support the different people in the change in order to better make them adhere to the change. Finally, the final objective is to measure the effectiveness of change. When presented with the Agile change management and the COOC method, our expert highlighted the fact that the first phase of the agile change model is paramount. If the change and its objectives are poorly defined from the beginning, the change project will not succeed. The important thing in a change project is to have a true vision of the project, why we will realize this project, but also to share and communicate around this vision.

He proposed a possible improvement point during the "define" phase which would be to include agility during this phase as well. A possible practical case would be to rely on indicators (such as Indexes of Engagement and Recommendations (IER)), harvested through digital interviews with employees of the company, Presenting a number of figures showing the need for change in the enterprise, so that the need for change is expressed by the employees themselves. Thus the future people concerned by the change will adhere from the beginning of the project. It will also be necessary to explain the ins and outs of the project so that individuals feel involved from the beginning of the project. It will thus be possible to involve individuals in the definition phase.

He found the experiment phase very interesting because it will allow people to experience change and experience it in real conditions. Providing and including on-demand training (training cycles) is also an interesting element that can be applied in companies.

Our expert thinks that the agile change model is applicable in a real company and that's very important. The tools presented in the COOC method will allow a good definition of the change and then a good adoption of the change by the concerned collaborators. The "anchor" phase of the change will flow if the definition and experimentation phases have been correctly carried out, so individuals will more easily assimilate the change or changes in the enterprise. We will still have to be careful that the pace of change is not too high, because people may have enough after a while.

\section{Discussion on the evaluation}

In the case study (migration of employees from BANK A to BANK B), we highlight the fact that if the agile change had been adopted, the change would certainly have been adopted as well. Less reluctance would have been shown as people would have been more implied in the change process and decisions. However, the case study, even if based on real facts, is only a hypothetic one as we only pinpoint the areas where an agile change management could have been an improvement.

The interview with the IT manager, who already deal with change management, highlights the qualities of the agile change model and the COOC method. In a change project or a change management project, it is vital to involve the people involved in the future change from the beginning of the project. It emerged from the interview that the phase of experimentation allows to involve all stakeholders. Nevertheless, there is a future improvement axis which will consist in adding agility to the define phase of the method. Another important point emerged from this interview: the COOC method is applicable in enterprise, it is not a utopian methodology.

\section{CONCLUSION}

With an increasingly competitive global market, companies around the world must be increasingly efficient and innovative in order to satisfy their customers. This global context leads companies to adapt to the new requirements of their customers so as not to lose market shares to decline and disappear. Companies are therefore forced to change more and more often and more quickly.

In the context of Industry 4.0, companies announce profound changes that will have a lot of implications on its employees. Defining a vision, strategy and goal for Industry 4.0 projects, setting up a change project plan as well as employee involvement are central factors for effective change management. Accomplishing changes will be very difficult without a company culture that supports those changes as experiences of change can be traumatic for the employees of a company and for the company itself. Agile methods, widely used in the world of IT development, bring a different vision to project management and offer better guarantees for project success. Agility echoes agile methods, widely used in the world of computer development. We made a questionnaire to evaluate the impact of people implication in a change project and highlight its importance. We concluded that an agile change management should help the change adoption in the process of a change project (RQ 1).

Building on the agile change model of $[1,15]$, we have provided the tools to drive agile change and thus make change agile: the COOC (Concept Of Continuous Change) method. We evaluate the method by a retrospective case study on a bank migration and an expert interview. These assessment tools determined that the COOC method should allow a better adoption of the change by the impacted collaborators (RQ 2).

However, this method has a big limitation: by perpetually redefining change during the "Experiment" phase, one of the risks would be that the change would remain at the word stage and would never really be implemented. Another limitation is that the fact that the company is in perpetual change could prove to be extremely resource-consuming and the change could be detrimental to the company's main activity. The question that can be raised would therefore be How can an enterprise can make performant business activity by continuously change?

An on-going perspective is to actually find two similar change projects in order to use the COOC method in a real case and to have a real comparison with another method. The use of indicators will help to define if the change is going on smoothly or not in all its phases and if the proposed tools are really pertinent.

Another improvement is to define a bigger set of tools in each of the phases, to apply accordingly to the context of the change project. Our questionnaire already highlights some of the criteria that could be of use to decide between the tools but there are a lot more of them and a bigger study is required to define them.

\section{REFERENCES}

[1] D. Autissier, K. Johnson and J-M. Moutot, « De la conduite du changement instrumentalisée au changement agile », Question(s) de management 2015/2 ( $\left.{ }^{\circ} 10\right)$, pp 37-44, 2015

[2] A. Weiss, A. Huber, J. Minichberger, M. Ikeda, "First Application of Robot Teaching in an Existing Industry 4.0 Environment: Does It Really Work?", Societies 6 (20), 2016 
[3] M. Trojani, «Industrie 4.0 : mettre l'humain au coeur de la transformation ", blog SAP, https://news.sap.com/france/2017/12/ industrie-4-0-mettre-lhumain-au-coeur-de-la-transformation/, 2017

[4] F. Becker, "Organisational agility and the knowledge infrastructure", Journal of Corporate Real Estate, Vol. 3 Issue: 1, pp.28-37, 2001

[5] The Agile Alliance, "The Agile Manifesto", 2001

[6] D. Autissier and J-M. Moutot, «Méthodes de conduite du changement», 2ème édition : «Diagnostic - Accompagnement Pilotage », Dunod, 2010

[7] J-P. Vickoff, «Méthode Agile, Les meilleures pratiques, Compréhension et mise en œuvre », QI, 2009

[8] K. Lewin, "Psychologie dynamique : les relations humaines", Presses Universitaires de France, 1935

[9] D. Autissier and J-M. Moutot, « La boîtes à outils de la conduite du changement », Dunod , 2013

[10] G. Teneau, "La résistance au changement organisationnel : Perspectives sociocognitives", Broché, 2005

[11] J. P. Kotter, "Leading Change", Harvard Business School Press, 2012

[12] R.M. Kanter, "The Change Masters", Simon and Schuster, 1983

[13] L. Dietze, "Putting people front and center: user-centered change", ThoughtWorks

blog, https://www.thoughtworks.com/insights/blog/putting-people-frontand-center-user-centered-change, 2017

[14] P. Alsher, "5 Implications for Change Management in an Agile World", IMA blog, https://www.imaworldwide.com/blog/5implications-for-change-management-in-an-agile-world, 2018

[15] D. Autissier and J-M. Moutot, « Le changement agile, Se transformer rapidement et de manière durable », Dunod, 2015

[16] A. Uzan, "Outils pour diriger : faire adopter le changement", 2017

[17] G. Benoit-Cervantes, « La Boîte à outils de l'innovation », 2e édition, Dunod, 2008

[18] M. Combe, "Change Readiness: Focusing Change Management Where It Counts", PMI White Paper, 2014

[19] F-X. Duperret, J-M. Moutot and D. Autissier, "Passez en mode workshop agile ! 50 nouveaux ateliers pour améliorer l'agilité de votre équipe", Pearson, 2018

[20] A. Rondeau, "Comprendre, mesurer et développer la capacité à changer des grandes entreprises", 2003

[21] C. Torrelles, J. Coiduras, X. Carrera and S. Isus Barado, « Du changement dans l'évaluation du travail d'équipe : validation de l'outil RUTE », 2014

\section{APPENDIX A : QUESTIONNAIRE FOR ICAP BAROMETER AND} WISHED VALUES, FOLLOWING [6]

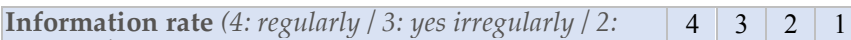
yes once / 1: never)

Have you heard of the project?

Did your hierarchy introduce you to the project?

Did you receive any information about the project?

Did you search for information about the project?

Comprehension rate (4: yes exhaustively / 3: yes

partially / 2: no but I would like / 1: no at all)

$\begin{array}{llll}4 & 3 & 2 & 1\end{array}$

Do you understand the objectives and terms of the project?

Have you solicited people or experts for a better understanding of the project?

Do you have a clear idea of what will change for you in your activity?

Have you looked on the project and its topics?

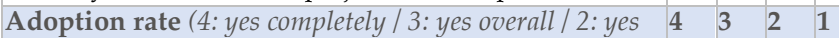
a little / 1: not at all)

Do you think this project is useful for the community?

Do you think this project is useful for your business?

Do you think this project is well received by the individuals concerned?

Do you think that all the conditions are met for the success of the project?
Participation rate (4: yes it is a priority / 3: yes in a \begin{tabular}{l|l|l|l|}
4 & 3 & 2 & 1
\end{tabular} partial way / 2: no but I would like / 1: no and it does not interest me)

Have you participated in project meetings?

Have you produced diagnostics, analyses and proposals for the project?

Have you considered integrating the elements of the project into your activity?

Have you tested some elements of the project in your activity?

\begin{tabular}{|c|c|c|c|}
\hline \multicolumn{4}{|c|}{ Wished information rate } \\
\hline Scale & Signification & Phase & Rate \\
\hline $0-25 \%$ & No information & Annoncement & $25 \%$ \\
\hline $25-50 \%$ & Partial Information & Exploration & $50 \%$ \\
\hline $50-75 \%$ & Irregular Information & Experimentation & $75 \%$ \\
\hline $75-100 \%$ & Complete Information & Déployment & $80 \%$ \\
\hline \multicolumn{4}{|c|}{ Wished comprehension rate } \\
\hline Scale & Signification & Phase & Rate \\
\hline $0-25 \%$ & No Understanding & Annoncement & $25 \%$ \\
\hline $25-50 \%$ & $\begin{array}{c}\text { Wished } \\
\text { Understanding }\end{array}$ & Exploration & $40 \%$ \\
\hline $50-75 \%$ & Partial Understanding & Experimentation & $60 \%$ \\
\hline $75-100 \%$ & $\begin{array}{c}\text { Complete } \\
\text { understanding }\end{array}$ & Déployment & $80 \%$ \\
\hline \multicolumn{4}{|c|}{ Wished adoption rate } \\
\hline Scale & Signification & Phase & Rate \\
\hline $0-25 \%$ & Rejection & Annoncement & $45 \%$ \\
\hline $25-50 \%$ & Low adoption & Exploration & $20 \%$ \\
\hline $50-75 \%$ & Partial adoption & Experimentation & $60 \%$ \\
\hline $75-100 \%$ & High adoption & Déployment & $80 \%$ \\
\hline \multicolumn{4}{|c|}{ Wished participation rate } \\
\hline Scale & Signification & Phase & Rate \\
\hline $0-25 \%$ & No participation & Annoncement & $20-40 \%$ \\
\hline $25-50 \%$ & Low participation & Exploration & $40-60 \%$ \\
\hline $50-75 \%$ & Partial Participation & Experimentation & $60-80 \%$ \\
\hline $75-100 \%$ & High Participation & Déployment & $80-100 \%$ \\
\hline
\end{tabular}

\section{APPENDIX B : CHANGE EVALUATION GRID}

Context

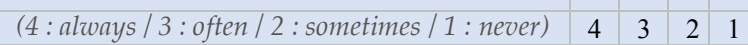

Has the external environment (economic, political, social) had an impact on employees' perceptions and practices regarding change?

Is change a priority for the company's manager(s)?

Is there a real culture of change in the company?

Does the company strategy propose operational change projects?

Is a change management method and/or tools available to employees?

Content

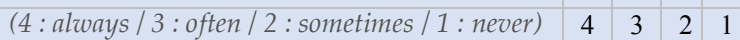

Do employees assess the level of change in the situations

they face?

Do employees change the way they do things after the change?

Do employees have the opportunity to assess their ability to change themselves?

Do employees have an idea of their own ability to change

their employees?

Is the management of change subject to a recognised and valued competence in the company?

Process

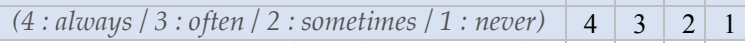

Do employees communicate with each other on the

changes to be made and how to do so?

Do employees use the tools and resources available to

them in terms of change management?

Do employees define themselves as relays of change

Do employees see change as an opportunity to improve

the existing one?

Are there indicators and/or tools for managing change? 